\title{
Challenges and Support for LGBTQ+ At-Risk Youth
}

\author{
Dorothy L. Reynolds \\ Department of Sociology, MacEwan University
}

\begin{abstract}
The number of people who identify as LGBTQ+ has been increasing, especially amongst young people. The LGBTQ+ community faces many challenges. This paper examines responses to at-risk youth who identify as LGBTQ+ in Edmonton, Canada and L'viv, Ukraine from a family structure level, social support structure level, and governmental programs or policies. It also explores how different reactions - such as feminism or patriarchy - have specific implications for these youth. Finally, it looks at how support, activism, advocacy and acceptance, or fear and anger, can create a change within society.
\end{abstract}

\section{Introduction}

The growth of the LGBTQ+ community within the "millennials" generation is a wave that has hit Canadian society. GLAAD, an American non-governmental group that monitors media in regard to LGBTQ+, has reported that in a survey done in the United States in 2017, $20 \%$ of millennials identified as LGBTQ (GLAAD, 2017). This wave of identification is going to creates an opportunity for those of other generations to come out and acknowledge their own gender non-conforming identities. Canadian and American societies need to be ready for this increase. The LGBTQ+ (lesbian, gay, bisexual, transgender, queer, +) community has been marginalized since before they had the ability to find each other, actually organize, and become a community. Yet, they have been around for all of human history. What are the challenges for LGBTQ+ youth? They have a harder time gaining human rights and acceptance because they are a marginalized group within our society. This becomes an even bigger problem for youth when they are considered at-risk. At-risk youth are children who have ended up in situations that have placed them at a higher risk for exposure to unstable or non-existent housing, risky behaviours, sexual exploitation, inconsistent or non-existent food sources, exposure to drugs and/or alcohol, dangerous peer groups or abusive, neglectful, and/or unavailable parents. Now put all those possibilities together and add in the extra complication of youth who identify as LGBTQ+.

The LGBTQ+ community is already a minority group. The attitudes of many patriarchal societies have been such that LGBTQ+ people are not always safe if they are perceived as belonging to this community. Therefore, their existence makes them more vulnerable to the possibility of becoming victims of any of the factors that make up at-risk youth. They have higher rates of being bullied, discriminated against and assaulted (sexual and otherwise) than the rest of the population. In a Statistics Canada survey done in 2014, it was found that the odds of being a victim of violent crime were two times higher for someone identifying as LGBTQ+, and someone identifying as bisexual was nine times more likely to be sexually assaulted (Simpson, 2018). Seventynine percent of those who identified as being lesbian or gay reported that they had been discriminated against in the last five years (Simpson, 2018). This vulnerability seems to indicate that they are particularly prone to becoming at-risk. A child from the LGBTQ+ community needs some tailored assistance, consideration and guidance when they do become at-risk, in order to help them after they have entered this category. This rise in the population of this community would warrant knowing how to help guide them when they need assistance.

What are some of the challenges of social implications on LGBTQ+ youth? The changing of a society's perceptions has a direct effect on LGBTQ+ people, whether it is in a negative or a positive way. This paper will take an intersectional feminist approach - proposing that all genders of all ethnicities deserve equality - and show how patriarchal society's hegemonic ideals create challenges for LGBTQ+ at-risk youth. Hegemony does not make space for anyone who is "other" to exist in harmony with the rest of society. This is perpetuated through patriarchy, which is a system of society or government in which men hold the power and all other genders are largely excluded from it. This paper will also show the challenges and the direct effects that having a child or family member who is LGBTQ+ can change the perceptions within the first social structure we are exposed to, the family unit. When people lack experience with, or 
knowledge about, LGBTQ+ persons (which often occurs within a patriarchal, hegemonic social structure), it is possible for homophobia to appear and dominate within a society. Changes in peoples' perceptions of, and subsequently reactions to, those in the LGBTQ+ community, have the ability to create change in society. Some of the ways that it can be improved is through feminism, advocacy, activism and acceptance; conversely, ongoing patriarchal hegemony will continue to repress LGBTQ+ persons. Shifts in attitudes can either be in the direction of tolerance and acceptance or intolerance, anger and fear. These perceptions are different in the countries of Canada and Ukraine, and therefore directly affect LGBTQ+ at-risk youth.

\section{Challenges at a Parental Level}

Where would these attitudes need to start in order to take hold? The first and most immediate impact occurs to an individual at the social structural level of the family. For LGBTQ+ youth this can be between themselves and their parents. Parents' perceptions towards their LGBTQ+ children have the ability to not only change their child's perceptions of themselves, but to also to change the parents' views of themselves (Gonzalez, Rostosky, Odom, \& Riggle, 2013). The parents' choice of acceptance or non-acceptance of a child's LGBTQ+ identification has an effect on the children. The hegemonic structure of patriarchal societies, where only the young, heterosexual, white male is the ideal, leaves little space for any alternatives to exist. Societies that are patriarchal and for which nonacceptance is the norm, can often result in parents abandoning these children, disowning them, abusing them physically, emotionally, and/or sexually. This can result in higher rates of suicide and depression for these youth (Hatchel, Merrin, \& Espelage, 2018). Youth are already at a high risk of suicide. The Centers for Disease control and Prevention and the National Center for Injury Prevention and Control found that in 2013, for youth 15-24 years of age, suicide was the second leading cause of death. For LGBTQ+ youth the rates are even higher for suicidality and relating behaviour. Studies have even found that these same results for LGBTQ+ have been reproduced by numerous sampling methodologies. For example, community-based samples, nationally representative samples, and even across various countries showed similar results for LGBTQ+ individuals (Garofalo, Wolf, Kessel, Palfrey, \& Durant, 1998; Lewis, 2009; Russell \& Joyner, 2001).

\section{Challenges at a Societal Level}

Societies for which religion perpetuates a patriarchal structure and appears to discriminate against those who identify as LGBTQ+ can deal a double blow to those with alternative sexual identities. This appears to be the case in Ukraine, where homophobia is evident in many ways. In and analysis of LGBTQ+ rights in Ukraine, Martsenyuk (2012) suggests that despite being a nation that has decriminalized homosexual acts between consenting adults, Ukraine is still a long way from acceptance. She points to the media and politicians for perpetuating homophobic attitudes. It is important to note that this paper was written before Ukraine's 2015 revolution. However, the state media (specifically television) is still mainly owned by Ukrainian oligarch's, some of whom do not even live in Ukraine anymore. All of these oligarchs are white, male and heterosexual, and perpetuate patriarchal hegemonic ideals and homophobia through their media holdings. In the article "The Paid Word, Who Owns Ukrainian Media", Vitalii Rybak (2019) reports that 75\% of Ukrainians still regularly watch television programing owned by the oligarchs'. They are therefore the central ones in control of what citizens of Ukraine are exposed to, media wise. Politicians are still being accused of being puppets for these oligarchs in order to control the country

Martsenyuk (2012) also suggests that there is an effort put forward by some groups from the ultra-right to use church to inflate homophobia. They use the LGBTQ+ community as an "other" to be fought against, a "common enemy". She points to a protest against homosexual propaganda and the juvenile justice system in March of 2011 by a group well known in L'viv. Included amongst the organizers were student unions and student governments from undisclosed universities in L'viv. They had such slogans as "Today the rescue of ukraine and of yourself depends on you! say yes to God and no to perversion!" and "position of Lviv youth and the younger generation of ukraine: let's preserve Christian and traditional family values in ukraine" (Martsenyuk, 2012. Elita natsiï, 2011).

Neither of these answers show signs of acceptance of anyone in the LGBTQ+ community, let alone at-risk youth. In fact, homophobia cannot happen without those persons, who are homosexual, to fear. Homosexuality has existed throughout human history. In fact, it happens in animals as well. What happens in countries like Ukraine to individuals who are LGBTQ+ is that they are forced to hide their true selves in order to survive within a homophobic society. Canada is not without flaw either, in that historically, patriarchy has been hegemonic here as well. In Edmonton, Canada, while community agencies visited by this author acknowledged the existence of the LGBTQ+ community, most admitted they had very little or no policies in place to deal with LGBTQ+ youth. There was even an acknowledgement of a lack of training with their staff about the LGBTQ+ community. However, all the agencies were taking steps to rectify their shortcomings. 


\section{Support at a Parental Level}

Alternatively, societies where parental acceptance is a possibility leads to other outcomes. Parental acceptance can result in change and growth for both the children and parents. Using a feminist lens to recognize that all gender identities are equal, there is the possibility of space being made for LGBTQ+ youth and a chance at acceptance. Parents have the potential to gain as much knowledge and growth from their children as their children do from them. Gonzalez and colleagues studied the positive aspects of being a parent of an LGBTQ+ individual among families in the United States, Canada, England, and South Africa (Gonzalez, Rostosky, Odom, \& Riggle, 2013). They found that parents learn and grow from interacting with their children, and that these interactions can help with parental cognitive and emotional development. They conducted an open-ended survey with 142 parents of LGBTQ+ children. Of those parents, 95\% noted at least one positive aspect of being a parent of a child that identified as LGBTQ+. Five positive themes that emerged from parents' comments: personal growth, positive emotions, activism, social connection, and finally closer family.

The first theme, positive growth, was reported by $56 \%$ of the parents. This theme was broken up into a further four categories: 1) becoming more openminded, 2) learning new perspectives, 3) attaining a greater knowledge and awareness of discrimination, and 4) developing deeper compassion (Gonzalez et al, 2013, pp. 328-329). The parents that reported becoming more openminded conveyed a sense of having to challenge or stretch themselves in order to step out of their "comfort zones" (Gonzalez et al, 2013, p. 329). By doing this, they began to rethink and question what they thought about not only the LGBTQ community but the world. This rethinking made them more open to new experiences. The parents also conveyed an improvement on family relationships. Among the parents that reported adopting new perspectives, some reported that they began to "reconsider and reevaluate previously held beliefs"

(Gonzalez et al, 2013, p. 329). This led to exposure to new and enriching worlds and perspectives on not only their lives but on society, and a new outlook on LGBTQ+ people. They also reported that this led to less rigid and more flexible views. In fact, "parents indicated that they were actively taught by and learned from their LGBTQ children. Many parents pushed themselves to learn more about the LGBTQ community because of their LGBTQ child" (Gonzalez et al, 2013 , p. 329). This leads to awareness of discrimination. The parents reported that their new open mindedness led to a new "awareness of discrimination and prejudice toward all minorities, including sexual and gender identity minorities" (Gonzalez et al, 2013, p. 329). Being made aware of these also led to an awareness of some parents to understand that they possessed a heterosexual privilege that many others do not. This awareness of the many forms of discrimination, not just toward their child but to other persons worldwide, left parents feeling that they developed a much deeper compassion for those who are disadvantaged.

The second theme, positive emotions, was reported in $41 \%$ of the participants. The most reported emotions were pride and unconditional love. Pride was not only for their children but pride in themselves for getting to have the opportunity to share in and help with the journey their child was on. They had a sense of satisfaction at the support they had been able to give to their child. Unconditional love was the other emotion. Parents reported not really caring about their child's sexual orientation, that it had no effect on how they felt about their child. They stated that there was no difference between how they felt about their LGBTQ+ child and their heterosexual child. They were simply loving and admiring of their unique attributes and accomplishments, just like any other child.

The third theme, activism, was reported in $33 \%$ of the parents. They often conveyed that this activism gave a new meaning or purpose to their lives. Activism manifested itself in a variety of ways. For some parents it was joining groups such as PFLAG (Parents, Families and Friends of Lesbians and Gays). For others it was helping other parents of LGBTQ+ youth with acceptance of their child's identity. Some even mentioned the rewards of being there for other LGBTQ+ person's when their own families did not support their sexual orientation. Others found their way to activism of all kinds, in many forms, to bring meaning and purpose to their lives. In summary, parents who participated in activism, educational efforts, and/or provided social support to LGBTQ+ people created new and positive sources of meaning to their lives. The orientation of their child compelled them to not only engage within their own family, but to also engage on local, national and international levels.

The fourth theme, social connection, was reported by $31 \%$ of the participants. These connections were directly related to their LGBTQ+ child and were connections they probably would not have made any other way. The main group mentioned was PFLAG, in their local, national and international capacities. These connections led to new friendships, a wide variety of activities, and advocacy.

The fifth and final theme, closer family relationships, was reported by $20 \%$ of the participants. This was through either feeling closer to the child, or a family closeness. The closeness to the child was deepened due to the loss of a secret (the child keeping their sexual orientation from their parent), as they viewed that secret as creating a distance between them. With that secret gone, there was space to create a deeper connection. The tightening of the closeness 
of the family was through going through the journey of their LGBTQ+ child together with other members of the family. That this journey strengthened their family bonds. These five themes are all positive effects for people regarding social structure, acceptance and happiness. These themes may even transcend just benefiting people within the confines of a family, but positively impacting other social institutions as well.

Parental support was not just a selfish endeavour that only saw benefits for themselves, it helped with their LGBTQ+ children. Hatchel, Merrin \& Espelage (2018) found that parental support was correlated with reduced suicidality and improved feelings of school belonging. This would indicate that parental support is important for the well-being of LGBTQ+ youth. With parental support appearing to be vital to an LGBTQ+ youth's well-being, what happens when it is not there, and the child is lacking those supports? That is when they end up in the government's or another organization's care. There are some parents that voluntarily give up their children to be placed into foster care, or even kick them out (making them homeless) because they cannot handle their child's behaviours. These rejected and ejected children are more often LGBTQ+ than not (Nouriel \& Harris, 2018).

\section{Support at a Societal Level}

While acceptance can be beneficial to the child and to the parent, it can also benefit society. Acceptance can be encouraged through activism and social media. Activism that is focused on LGBTQ+ rights as human rights has the ability to change society's perception and cause a ripple effect to other segments of society. For youth in Canada, there are Gay Straight Alliance groups within schools to help advocate for acceptance and awareness. Amnesty International is another group that has school chapters throughout the world. They promote human rights issues on a global scale, which would fall into the feminist perspective of equality for all members of society. Their exact policy concerning the LGBTQ+ community is:

“A person's sexual orientation or gender identity can lead to discrimination, violence, imprisonment, torture or even execution, and these abuses are all illegal under international human rights law. Amnesty International works to protect the rights of lesbian gay, bisexual, transgender, and intersex (LGBTI) people by shining a light on abuses, calling for policy change and working to protect LGBTI human rights defenders" (Amnesty International. June 2019)

Bringing visibility to a group that has been made to feel invisible is a key step. One of the ways that this visibility is happening in Ukraine is through their first openly LGBT singing group called Qwerty Queer. They have even been featured in mainstream Ukrainian media, helping to raise visibility and awareness to the existence of the LGBTQ+ community within that country. There was only one group that was found in Ukraine that is a support system for those who identify as transgender. This was called Insight, and even their webpage claims that they are the only group in the country that is working with this community on many levels (Insight, 2019). They do research on the transgender community, set up meetings in safe spaces, and work with doctors to help improve their knowledge of medical issues concerning the transgender community. Finally, they work with international organizations, like Human Rights Watch, about the situation facing those who are transgender in Ukraine.

\section{Challenges at the Meso Level}

Within any country, by having groups advocate for social support organizations such as social workers, at-risk youth support systems, health care, and law enforcement, to have policies in place that include LGBTQ+ youth, there is the chance for acceptance. Advocacy increases visibility, which makes these organizations aware of the LGBTQ+ community and learn how to deal with the extra complexities of their situations.

There are many organizations that are in place to deal with at risk youth. There is the question of whether these organizations are including members of the LGBTQ+ community or not. When patriarchy is hegemonic, there is little space for these individuals, rendering them invisible. This alters the perceptions of its citizens to follow these ideals. If you are not white, young, heterosexual, and male, you do not matter. The counter to this is to use a feminist perspective where the focus has to be on changing the perception to encompass the idea of inclusion and equal rights of LGBTQ+ of all races, ethnicities, and religious affiliations. This is a matter of human rights. A look at the American foster care system showed that LGBTQ+ youth are overrepresented there. Research in Los Angeles, California finds that $19 \%$ of children in child welfare could identify as LGBTQ+ (Nouriel \& Harris, 2018). If these children are becoming such a big part of the system, the logical progression should be to put policies in place to help them. By acknowledging that LGBTQ+ children exist, the conversation can start about how to implement extra training to help when they end up in unfortunate circumstances.

\section{Challenges at the Macro Level}

Changes to a government are almost always slow. Activism can teach LGBTQ+ persons and advocates to learn to work within the existing system. In Canada, the Canadian Charter of Rights and Freedoms (section 15) protects equality for individuals, including discrimination in regard to their sex. 
Snow (2017) analyzed Ontario's All Families Are Equal Act (AFAEA) and contends that there were three factors that happened during the policy debates that contributed to its implementation. They were the use of an organized witness group with legal expertise, inflating the use of "rights talk" to increase the scope of the ruling, and using the Charter of Rights and Freedoms to keep the effect of Progressive Conservatives to a minimum. Through these means, LGBTQ+ and assisted reproduction advocates were able to get the All Families Are Equal Act passed. While this example does not use LGBTQ+ youth specifically, it does show how advocacy for that community at large can mobilize to achieve a goal, within the existing legal system that can benefit its members.

\section{Discussion and Conclusion}

There are many challenges concerning LGBTQ+ youth. The first social structure that presents the most immediate challenges is within families. The choice by parents is to either accept or not accept their children. Both parental decisions present challenges to the child, although it would appear that acceptance from parents causes the least amount of challenges for both the child and the parent. Challenges that arise for these children from non-acceptance can lead to suicidality, abuse, neglect and so on. Supports in place for both parents and children can have extremely positive, sometimes even life altering results. Challenges for society are when the church, media, social structure, and so on are all centered around impossible patriarchal hegemonic ideals. Making sure that supports are in place at a societal level are crucial for LBGTQ+ youth. Challenges at a Meso level are finding ways to make sure that LGBTQ+ youth are included within our support structures. At a Macro level the challenges are making sure that if there are human rights laws in place they are being adhered to by governments.

By understanding what perceptions people have, and how they develop these perceptions, there is the possibility of affecting change. If the number of youths who identify as LGBTQ+ continue to rise, it is only a matter of time before everyone has someone in their family that belongs to that community. Having the intimate connection of having a member of your own family belong to a community makes it more personal and relatable to people. Those interactions have the ability to change a person's views on things. Through advocacy, society can help this marginalized and discriminated group of children so they can have the same basic human rights as other children. By changing adult perceptions at an individual level, there is the possibility of creating change that can have a ripple effect throughout all social systems that can benefit LGBTQ+ at-risk youth. In fact, it could benefit LGBTQ+ members of all ages as well as other members of society. Through advocacy, inclusion, and awareness, social support systems from nonprofit to government child assistance services can be enticed to change their policies, both at a municipal and federal level. By working toward changing or adapting laws to ensure that they include LGBTQ+ rights and voting in candidates or parties that support LGBTQ+, the individual can take their advocacy to a federal level. Therefore, it is possible that with perceptual societal shifts, change can occur throughout society for these children and others. As Maya Angelou said: "Do the best you can until you know better. Then when you know better, do better."

\section{Acknowledgements}

The Author would like to acknowledge the support and services of MacEwan University, Ukrainian Catholic University and Dr Michael Gulayets. Grants for the author were provided by MacEwan International Education Abroad Award and the MacEwan UFCE Award.

\section{References}

All Families Are Equal Act (Parentage and Related Registrations Statute Law Amendment), 2016, S.O. 2016, c. 23 - Bill 28.

Amnesty International (2019) "LGBTI rights are human rights". Retrieved June 2019, from https://www.amnesty.ca/ourwork/issues/lgbti-rights accessed June 22, 2019

Canadian Charter of Rights and Freedoms, s 7, Part I of the Constitutional Act, 1982, being Schedule B to the Canada Act 1982 (UK), 1982, c11

Centers for Disease Control and Prevention, National Center for Injury Prevention and Control. (2013). Web-based injury statistics query and reporting system. Retrieved from http://www.cdc.gov/injury/wisqars/

Elita natsiï. 2011. "Lvivska molod zakupila vaselin dlia deputativ" (youth in Lviv Bought Vaseline for the Deputies) Retrieved April 3, 2011,from http://elitanatsii. com/articles/ukrainians/377-youthbought-vaseline-for-members.html,

Families Are Equal Act. Canadian Journal of Law and Society, 32(3), 329-348. doi:10.1017/cls.2017.24

Garofalo, R., Wolf, R. C., Kessel, S., Palfrey, J., \& DuRant, R. H. (1998). The association between health risk behaviors and sexual orientation among a school-based sample of adolescents. Pediatrics, 101(5), 895-902.

GLAAD. (2017, March 30). New GLAAD study reveals twenty percent of millennials identify as LGBTQ. Retrieved May 2019, from https://www.glaad.org/blog/new-glaad-study-reveals-twentypercent-millennial-identifylgbtq May 2019

Gonzalez, K., Rostosky, S. S. Odom, R.D. \& Riggle, E.D.B. (2013). The positive aspects of being the parent of an LGBTQ. Child Family Process, 52, (2), 325- 337 oi: 10.1111/famp.12009

Hatchel, T., Merrin, G.J \& Espelage, D. (2018).Peer victimization and suicidality among LGBTQ youth: The roles of school belonging, self- compassion, and parental support. Journal of LGBT Youth, 16(2), 134-156. 
Insight. (2019). Transgender Program. Retrieved from https://www.insight-ukraine.org/en/projects/transgender

Lewis, N. M. (2009). Mental health in sexual minorities: Recent indicators, trends, and their relationships to place in North America and Europe. Health Place, 15(4), 1029-1045.

doi:10.1016/j.healthplace.2009.05.003

Martsenyuk, T. (2012) The State of the LGBT Community and Homophobia in Ukraine. Problems of Post-Communism 59 (2), 51 62.

Nouriel, A.E., \& Harris, V.W. (2018) An Intersectional Feminist Perspective on LGBTQ Youth in Foster Care : Implications for Service Providers. World Journal of Education, 8(4), 177-187, doi:10.5430/wje.v8n4p177

Russell, S. T., \& Joyner, K. (2001). Adolescent sexual orientation and suicide risk: Evidence from a national study. American Journal of Public Health, 91(8), 1276-1281.

Simpson, L. (2018) Violent victimization of lesbians, gays and bisexuals in Canada, 2014. Retrieved from https://www150.statcan.gc.ca/n1/pub/85-002x/2018001/article/54923-eng.htm

Snow, D. (2017) Litigating Parentage: Equality Rights, LGBTQ Mobilization and Ontario's All Families Are Equal Act. Canadian Journal of Law and Society, 32(3), 329-348.

doi:10.1017/cls.2017.24 